\begin{tabular}{c|c|c|c|c|c|} 
Revista Jangwa Pana & ISSN: 1657-4923 & Vol. 15 & No. 1 & 43 - 57 & Enero - Junio de 2016 \\
DOI: http://dx.doi.org/10.21676/16574923.1748
\end{tabular}

\title{
SALVAGUARDA DEL PATRIMONIO CULTURAL GASTRONÓMICO SANTANDEREANO
}

\section{CULTURAL HERITAGE GASTRONOMIC SANTANDEREAN SAFEGUARDING}

\author{
Luz Marina Rodríguez-Martínez ${ }^{1}$,Wilson Arturo Cáceres-Flórez ${ }^{2}$
}

\section{RESUMEN}

La finalidad del presente trabajo de investigación es diseñar una cátedra de Patrimonio Cultural Gastronómico del Núcleo Provincial Metropolitano de Santander, dirigida al programa profesional de Gastronomía y Alta Cocina de la UNAB. Esta investigación se ocupa de las costumbres alimentarias, la riqueza cultural, las tradiciones, los hábitos y los conocimientos culinarios como base fundamental del ser humano en la sociedad. Dichos elementos han sido definidos por la UNESCO como patrimonio cultural inmaterial. Preocupados por la pérdida de identidad cultural y de las raíces sociales relacionadas con los usos y costumbres gastronómicas; se recorrieron las plazas de mercado y hogares campesinos para entrevistar a cocineros y amas de casa, muchos de ellos provenientes del sector rural santandereano. Se realizó una categorización estructurada según las formas de alimentación, tradición y cultura, conocimientos culinarios y formas de preservación. Se encontró que dieciséis preparaciones están riesgo de desaparecer y que tanto estudiantes como chefs conocen los platos, pero no los preparan. Un aporte del programa de Gastronomía sería integrar la cocina tradicional a procesos académicos y desarrollar investigaciones que contribuyan a reconocer, valorar, preservar y divulgar, las expresiones culinarias ancestrales santandereanas.

Palabras Clave: Patrimonio cultural; gastronomía; tradición; identidad cultural; catedra; preservar

\section{ABSTRACT}

The purpose of this research is to design an academic guide about the Gastronomic Cultural Heritage of the Metropolitan Provincial Core of Santander. It is directed at the professional program of Gastronomy and Haute Cuisine at UNAB. This research works on food habits, cultural richness, traditions, habits and culinary skills as the foundation of human society. These elements have been defined by the UNESCO as intangible cultural heritage. Concerned about the loss of cultural identity and social roots related to the uses and gastronomic traditions; marketplaces and peasant households were visited to interview chefs and housewives, many from the rural sector in Santander. A categorization was structured according to types of food, tradition and culture, culinary knowledge and ways of preservation. It was found that sixteen preparations are in danger of disappearing, and that both students and chefs know the dishes but do not prepare them. A contribution of the Gastronomy program would be to integrate the traditional cooking processes to the academic processes and to develop research that contributes to recognize, measure, preserve and disseminate the ancestral culinary expressions in Santander.

Keywords: Cultural heritage; gastronomy; tradition; cultural identity; preserve

Tipología: Artículo de investigación científica y tecnológica

Fecha de recepción: 02/10/2015

Fecha de aceptación: 04/04/2016

Como citar este artículo: Rodríguez-Martínez, L.M. \& Cáceres-Flórez, W.A. (2016). Salvaguarda del patrimonio cultural gastronómico santandereano. Jangwa Pana, 15 (1), 43 - 57

1. Magister. Universidad Autónoma de Bucaramanga. Colombia. Correo electrónico: 1rodrima@unab.edu.co

2. Magister. Universidad Autónoma de Bucaramanga. Colombia. Correo electrónico: wcaceres@unab.edu.co 


\section{INTRODUCCIÓN}

$\mathrm{E}^{\mathrm{n}}$ n 1972, la UNESCO, consideró que la conservación del Patrimonio Natural y Cultural es vital para el desarrollo de su entorno. Dentro de las disposiciones generales en el Artículo 1 se estableció:

"La salvaguardia del patrimonio cultural inmaterial; el respeto del patrimonio cultural inmaterial de las comunidades, grupos e individuos de que se trate; la sensibilización en el plano local, nacional e internacional a la importancia del patrimonio cultural inmaterial y de su reconocimiento recíproco; y por último, el artículo estableció la cooperación y asistencia internacionales.” (Art. 1).

En el Manual de Gestión del Patrimonio Cultural de María Ángeles Querol se plantea la pregunta: ¿Para qué sirve el Patrimonio Cultural? La respuesta más acertada es el Patrimonio Cultural forja la identidad histórica de una comunidad, genera arraigo hacia la región y fortalece el derecho a disfrutar libremente las tradiciones culturales de cada pueblo. Asimismo, el patrimonio cultural contribuye a construir historia además de elevar el nivel cultural de las personas. Por su parte, (Querol, 2010) destaca que: "La utilidad realmente práctica del patrimonio cultural es el desarrollo turístico y todo lo que esta disciplina implica: gastronomía, viajes, hospedaje". Asimismo, Edgar Bolívar, profesor de Antropología de la Universidad de Antioquia, en su libro El patrimonio cultural: algo más que objetos, algo más que pasado indica que no todo lo que genera orgullo o lo que tiene valor debe ser asumido como patrimonio cultural. En este sentido, el patrimonio está conformado por bienes materiales e inmateriales y por valores que tienen un significado social, ya sea a nivel individual o colectivo, y que también son apreciados, conocidos y difundidos por una comunidad, además de estar relacionados estrechamente con su identidad.
Además en el patrimonio cultural acontece en un contexto multicultural y diverso donde deben estar involucradas las instituciones públicas y privadas que apoyen y rescaten la diversidad de costumbres, por ende la academia juega un papel fundamental.

"Cuando hablamos de patrimonio cultural estamos ubicados en un cruce de caminos donde confluyen no solamente las diferentes disciplinas sino también diversas formas de expresión, soportes de comunicación y por supuesto grupos sociales con intereses particulares. En esta cuestión están involucradas, las instituciones públicas, privadas, la academia, los medios de comunicación y la sociedad civil. Podemos decir que el asunto del patrimonio es interdisciplinario, intersectorial, intergrupal; es un punto medio donde se evidencia el poder de la memoria, de la producción de significados y un escenario donde se visibilizan e invisibilizan las formas culturales." (Nuñez, 2012, p. 41)

Teniendo en cuenta lo anterior, el Ministerio de Comercio Industria y Turismo de Colombia, apunta que la comida de una región se prepara con elementos que se producen en el área; desde ese momento y con este solo hecho, ya la comida preparada se abre un espacio dentro de la cultura del lugar, de su gastronomía y, por lo tanto, dentro de su producto turístico. Además, se debe resaltar que la gastronomía siempre resulta imprescindible a la hora de constituir esta categoría de productos turísticos, porque el visitante siempre deberá consumir alimento en el lugar a donde se desplazó. De este modo, se constituye un consumo muy particular y se experimenta parte de la cultura de una región.

Ahora bien, la comida típica santandereana es una de las más reconocidas del país; esta se ha caracterizado por su diversidad, por su riqueza 
gastronómica y por su compleja elaboración. Para el desarrollo de esta variada gastronomía han intervenido culturas de diversa índole, como las de los indígenas que habitaban estas regiones; ellos desarrollaron y heredaron a otras generaciones sus propias preparaciones basadas en el maíz. Por su lado, los africanos aportaron sus fogones y sus modos de preparar animales de caza, como el armadillo y el venado. De igual manera, los españoles, ingleses, franceses y alemanes, cada uno de ellos, aportaron elementos de su cultura culinaria a la cocina santandereana. Por esto, se debe tener en cuenta que la alimentación y las diferentes prácticas en las preparaciones hacen parte del patrimonio cultural inmaterial de un pueblo $\mathrm{y}$, por lo tanto, se deben salvaguardar para que las generaciones presentes y futuras distingan y conozcan el legado que deben preservar.

Es necesario comprender que la gastronomía no solo se concentra en el hacer, sino también en valorar el componente cultural y patrimonial que existe detrás de las prácticas culinarias. Por tal razón, es imprescindible reflexionar acerca de cómo determinar aquellos platos y productos que dan identidad a la cocina típica santandereana. Tampoco se pueden dejar de lado los orígenes las formas de preparación, los productos e ingredientes, las prácticas, los usos y los conocimientos. De allí se deriva que una forma de salvaguardar las manifestaciones del patrimonio cultural inmaterial es identificar las preparaciones culinarias que están en peligro de desaparecer, a fin de contar su elaboración, origen y tradiciones dentro de un módulo diseñado para la línea básica de conocimiento del programa profesional de gastronomía y Alta Cocina de la UNAB.

Las diferencias y semejanzas de los pueblos están caracterizadas por su cultura y su patrimonio que, de otra parte, enmarcan la distinción y símbolo de una raza. Para Kottak, el punto de vista del estudio social y cultural de los pueblos es muy importante porque, existen diferencias simbólicas y materiales. Por lo tanto, el estudio debe realizarse a partir de análisis lingüísticos, ambientales e históricos realizando una comparación e interpretación de las experiencias humanas. Para ello es necesario tomar los mitos, tradiciones y costumbres e imaginarios que cada comunidad tiene sobre sí (Kottak, 2006).

De esta manera, el patrimonio cultural obedece a la historia de los pueblos, a sus luchas y aventuras, que, a su vez, generan modos particulares de reconocimiento por parte de unas comunidades frente a otra. (García, 2011; Serrano, 2007; Pedro, 1977), es así como se entiende la importancia que tiene el acervo cultural, es decir, la identidad, para un pueblo.

Ahora bien, Colombia es un país con una enorme diversidad. En su geografía cultural se puede encontrar gran diversidad de grupos étnicos y distintas experiencias históricas acopiadas geopolíticamente; así también, se encuentran diferentes formas de comprender y asumir la vida desde su relación entre los vestigios culturales indoamericanos, africanos, europeos y asiáticos, que tanto contribuyen a orientar la identidad de cada comunidad y de los distintos grupos sociales y geográficos que constituyen Colombia.

Profundizando en el aspecto antropológico, es necesario observar que las colectividades se autodefinen por sus vivencias históricas propias y por su herencia cultural. Estas últimas también determinan los rasgos antropológicos de las comunidades, aunque dichas relaciones, simbólicas y de memoria, siguen siendo poco conocidas. Esto quiere decir que, en Colombia, las realidades antropológicas reconocidas desde la óptica de la historia han sido homogenizadas bajo estereotipos o prejuicios que superficializan el conocimiento profundo de la identidad de cada comunidad.

En relación con esto, algunos escritores han hecho un primer intento por encontrar los orígenes y conexiones simbólicas de las culturas con su memoria histórica. Por ejemplo, el sociólogo Enrique Serrano en su novela Donde no te co- 
nozcan devela los supuestos orígenes judíos de los santandereanos y a su vez, Pedro Gómez Valderrama los relaciona con los germanos en la novela La otra raya del tigre. Estas aproximaciones estéticas, desde la literatura, generan unas primeras lecturas culturales más orientadas hacia la investigación o, al menos, ofrecen miradas más reflexivas sobre la realidad regional. Dichas expresiones sugieren, entonces, que Santander es un departamento diverso y, por tanto, mezcla de diferentes etnias (Mindiola, 2006).

De otra parte, para la preservación del patrimonio cultural de los pueblos se deben tener en cuenta las colectividades y comunidades portadoras del conocimieto cultural gastronomico, pero para esto como lo manifiesta Querol, en su libro Manual de gestion del Patrimonio cultural: "Para seguir identificando la búsqueda, valoración y sistematización de las culturas, es necesario ir cualificando el manejo, disposición y preservación de patrimonios culturales, lo que requiere altos grados de procesos tecnificados y científicos, además de las claras bases teóricas y epistemológicas que estos procesos requieren" (Querol, 2010).

Esto se entiende, con mayor razón, si de manera muy juiciosa se caracteriza y se reconoce la gastronomía autóctona o típica de otras gastronomías. Este solo hecho, a menudo, puede ser fuente de confusiones, en este sentido, se deben destacar experiencias como la de la convocatoria "Somos Patrimonio" (Convenio Andrés Bello, 2006). El cual mostró las riquezas, pero a la vez los peligros que encierra el estudio del patrimonio de un pueblo, del mismo modo, estas experiencias formativas permiten conocer las diversas prácticas en gastronomía autóctona de la inmensa multiculturalidad colombiana "que son la expresión de tres condiciones: el crisol en que se ha fundido nuestra nación con su herencia indígena, europea y africana; la compleja diversidad ecológica, así como la rica y variada oferta ambiental de nuestro territorio y, finalmente, la historia particular de cada pueblo y región" (Sánchez \& Sánchez, 2006, p. 7).

De manera particular, la literatura acoge los significados de todas las formas de patrimonio, que con ayuda de la estética y del lenguaje desembocan, como en un mosaico, en la rica gastronomía típica del departamento de Santander. Como prueba de esto, la escritora que viajaba por el Cañón del Chicamocha narra que:

“...veía junto en un solo paraje los rosicleres, la paleta de pasteles en su espectro completo, la explosión de luz translúcida, la aparición nublada de la bruma del sol derramada a raudales en la tierra de Santander... con sus campos provocativos de sembradíos de yuca que hacía agua la boca con sus decorativas eras de ananás y el único sol, de profundo azul caliente Barichara, que sugerían acción y productividad". (De los Rios, 2002, p. 7)

Para la delimitación de este problema es necesario comprender que algunos fenómenos como la constante urbanización del Núcleo Provincial Metropolitano de Santander y el desconocimiento de la riqueza gastronómica local influyen de diferentes modos de percibir las tradiciones culinarias de una comunidad. El problema de la tradición se hace aún más complejo con la globalización debido a que esta ha propiciado la difusión de una amplia gama de opciones culinarias que representan una amenaza a la tradición gastronómica por empobrecer la cultura de consumo para la alimentación; el efecto de las políticas alrededor de las importaciones de alimentos es que las regiones pierden porque pueden hacer desaparecer las tradiciones gastronómicas locales.

Desde la segunda mitad del siglo XX y con mayor fuerza en esta parte del siglo XXI, en las zonas urbanas las necesidades alimenticias se satisfa- 
cen con comidas cada vez más universales y uniformes como las bebidas colas, hamburguesas, pizzas, sándwiches, comida pre-cocida, congelada y empacada. Este fenómeno es producido por las agitadas formas de vida, manejo de tiempo, actividad laboral o estudiantil acelerada, grandes distancias entre el hogar el trabajo y las ocupaciones del diario vivir. Dichos comportamientos generan nuevos hábitos culturales e individuales.

Por consiguiente, el consumo de alimentos con preservativos, saturados de químicos y de todo tipo de elementos artificiales en el sabor, olor y textura ha aumentado considerablemente. Así, preparar una comida con el ritual necesario para producir un plato natural se ha convertido en un lujo ocasional o ha quedado relegado solo a los restaurantes. Ciertas comidas típicas de la zona son muy elaboradas y requieren de utensilios especiales, así como de tiempos extensos de preparación como el cabrito, la pepitoria o la chanfaina; a tal punto de que se convierten en comida exótica $\mathrm{y}$, en consecuencia, van desapareciendo de los gustos y la cotidianidad de las personas. Este fenómeno empobrece paulatinamente los procesos de identidad cultural y social de la región y del país. Sin embargo, es posible minimizar el impacto de este ritmo de vida en la tradición culinaria si se logra hacer un inventario de los bienes y prácticas de carácter patrimonial.

Con base en lo anteriormente descrito nos preguntamos ¿Cómo estructurar una guía cátedra que recopile, visualice y promueva la conservación del patrimonio cultural gastronómico del Núcleo Provincial Metropolitano de Santander?

Cuando un conjunto de bienes son catalogados como materiales e inmateriales, nos encontramos ante la puesta en acción de unos criterios fundamentales: "la naturaleza, la historia y la inspiración creativa". Este proceso se ha denominado activación o legitimación de un patrimonio. Generalmente, se argumenta la "antigüedad", la "escasez" o la "nobleza" del elemento seleccionado, aunque no son factores que definen el valor patrimonial de un bien. El patrimonio y el turismo tienen una estrecha relación. La afluencia de visitantes dada la autenticidad de un bien patrimonial y su preservación incrementan o disminuyen los ingresos económicos (Cuervo, 1999).

Por lo tanto, se debe iniciar un proceso de rescate de los diversos aspectos del patrimonio histórico y cultural de la gastronomía, así como el reconocimiento, valoración y preservación por medio de la enseñanza- aprendizaje en las instituciones académicas que ofrecen el programa de gastronomía. Dicho proceso forma parte de la identidad de una región orgullosa de sus raíces y que en cada manifestación gastronómica encarna su idiosincrasia.

Es así como planteamos el objetivo general:

Identificar los platos típicos $\mathrm{y} / \mathrm{o}$ productos gastronómicos característicos del Núcleo Provincial Metropolitano de Santander que están en riesgo de desaparecer para contribuir al rescate del Patrimonio Cultural Gastronómico, por medio de una guía catedra que facilite su enseñanza-aprendizaje.

Y unos objetivos específicos:

Analizar las experiencias de recuperación del patrimonio cultural gastronómico de los países identificados por la UNESCO.

Identificar los platos típicos y/o productos gastronómicos característicos del Núcleo provincial Metropolitano que están en riesgo de desaparecer.

Estructurar los contenidos para el diseño de una guía catedra del patrimonio cultural gastronómico para el programa profesional de Gastronomía y alta cocina de la Universidad Autónoma de Bucaramanga, UNAB. 


\section{Santander Territorio de Cultura Gastronómica}

La región santandereana es una de las zonas que se ha caracterizado por la variedad de comida y porque requiere tiempo en el proceso de preparación entre los cuales las carnes juegan un papel predominante. Para el desarrollo de esta variada y deliciosa gastronomía, intervinieron culturas de diversa índole como la de los indígenas que habitaban estas regiones, como los chibchas, guanes, yariguies, chitareros, laches, saboyaes, agataes y carares; que nos enseñaron sus propias preparaciones a base de maíz, los alimentos envueltos en las hojas de los productos que consumían, como el plátano, el banano y el mismo maíz. Los africanos esclavos que llegaron a nuestro territorio traídos a la fuerza por los conquistadores del viejo mundo, aportaron elementos como fogones, asados y modos de preparar animales de caza; entremezclados con ellos, vinieron aventureros europeos, ingleses, franceses y alemanes. Cada país aportó parte de su cultura culinaria a la cocina Santandereana: los alemanes con sus embutidos y salamis, los españoles con sus capones y jamones; y los franceses con su técnica innata, cuna de la cocina moderna.

Pero no solo introdujeron al nuevo mundo su forma de preparar las comidas, sino que con ellos traían animales de diversa índole como el cerdo, cabras, ovejas, vacas y gallinas. Cada uno de estos animales se adaptó a cada región de nuestro país de acuerdo a su territorio y clima y, por ende, su contribución a nuestra cocina. Antiguos habitantes de la región, eran hombres altos y fuertes, hecho que atribuían a su alimentación a base de frutas, poca carne y mucho pescado. Obedeciendo a la historia, Santander y Norte de Santander poseen riquezas gastronómicas que otras regiones del país no tienen, a causa de emigrantes europeos provenientes de España y Alemania, que le aportaron variados sabores a los platos. A La cocina Santandereana llegaron también algunas fa- milias árabes, sirios, libaneses, palestinos, judíos y gitanos (Ministerio de cultura, 2012).

\section{MATERIALES Y MÉTODOS}

La investigación que se realizo fue de tipo cualitativo, pretende analizar y explicar una realidad social, además de reconocer el componente cultural y patrimonial que existe detrás de la cocina ancestral. Con ello se llegará a identificar aquellos productos gastronómicos que están en riesgo de desaparecer y se suministrará un instrumento para conservar sus orígenes y la preparación de estos. El documento acopiará los ingredientes que se utilizan y las prácticas culinarias, pero sobre todo contribuirá a la salvaguardia del patrimonio cultural inmaterial del núcleo provincial metropolitano de Santander, que comprende los municipios de: Bucaramanga, Floridablanca, Girón, Piedecuesta, Los Santos, Lebrija y Rionegro.

Lo anterior implica que el desarrollo de la investigación contemple las siguientes fases:

\section{Identificación de la muestra}

Los participantes en esta investigación son las personas que por su edad y por su residencia en la región son seleccionados como unidad de análisis, de acuerdo a los criterios establecidos por los investigadores: campesinos, amas de casa y cocineros empíricos de la región.

\section{Aplicación de las entrevistas estructuradas}

Recolección de información acerca de aspectos propios de la tradición gastronómica de la provincia objeto del estudio; niveles de identificación y apropiación de la cultura gastronómica local; las técnicas de elaboración empleadas en la preparación de los distintos productos; las prác- 
ticas y rituales dentro de los cuales los distintos productos cobran un significado cultural.

\section{Grupos focales}

Recopilar el aporte de quienes, por su residencia en la región, por su edad y su gusto por la cocina, pueden dar testimonio de las técnicas culinarias o prácticas culturales relacionadas con el patrimonio gastronómico de la provincia de la investigación. Por otra parte, se tomará un grupo de chef de restaurantes típicos del área Metropolitana de Bucaramanga y otro grupo serán los estudiantes del programa Profesional de Gastronomía y alta Cocina de la UNAB.

\section{Proceso de sistematización, análisis y presentación de la información}

Lo documental permitirá elaborar una trayectoria de la gastronomía de las provincias, así como de los diferentes eventos que han marcado la gastronomía local.

\section{Análisis de datos y triangulación de la información}

Revisión, ordenación, lectura y análisis de las entrevistas, información histórica documental y contrastación con los Chef y los estudiantes del programa profesional de gastronomía de la UNAB

En las provincias santandereanas hay aspectos de la tradición gastronómica que ameritan ser rescatados mediante una consulta basada en hechos reales, recorriendo los escenarios y entrevistando las personas que tienen información del patrimonio por conocer la tradición, la identidad gastronómica. Con este instrumento se podrá verificar si realmente estos productos han venido desapareciendo. Luego, se espera construir un documento donde queden consignados los aspectos más relevantes de este recorrido por patrimonio inmaterial culinario de Santander.
Se organizó una entrevista estructurada que se aplicó a 10 personas con criterios de inclusión previamente establecidos tales como personas entre 50 y 85 años, amas de casa, campesinos y cocineros de restaurantes típicos, residentes en el Núcleo Provincial Metropolitano de Santander (Girón, Floridablanca, Lebrija, Piedecuesta, Rionegro, Lebrija, Los Santos), que elaboren productos gastronómicos tradicionales.

Tomando como referencia la población escogida al azar y de acuerdo a los criterios anteriormente mencionados, se consultaron los lugares donde existían aquellos restaurantes típicos, plazas de mercado donde se encuentran las personas que comúnmente se ha tenido información y preparan comidas típicas en el área metropolitana de Bucaramanga. Para la triangulación de la información se tendrán en cuenta los restaurantes de comida típica reconocidos y ubicados en la zona metropolitana de Bucaramanga.

\section{Diseño de la encuesta estructurada}

Se diseñó una encuesta estructurada, de tal manera que al realizar la entrevista las personas no se condicionaran a una pregunta, si no que expresaran su sentir alrededor de ese producto o plato ancestral, su origen, identidad, cultura y evocación de sus recuerdos y tradiciones, ¿cómo aprendieron a cocinar?, ¿quiénes le enseñaron?, ¿cómo los elaboran?, ¿qué productos utilizan?, ¿cómo transmiten el conocimiento? y ¿quiénes le enseñaron?, ¿cada cuánto tiempo lo preparan?, ¿qué significa el producto gastronómico para sus vidas?,¿quiénes lo consumen? Luego, se hizo una prueba piloto de la entrevista a William López Flórez, chef de más de 20 años de experiencia, especialista en comida regional santandereana y con una vasta experiencia en este sector; se aclara que el chef no entra dentro de las personas entrevistadas. Posteriormente, se hicieron las correcciones pertinentes al instrumento, tomando en cuenta sugerencias dadas por el chef avalador. 


\section{Registros}

Se solicitó agendar un tiempo y lugar de la entrevista con cada persona.

\section{Intervención}

Se hizo una intervención directa con las personas.

\section{Rol de intervención de los participantes}

Los participantes expresan sus saberes, orígenes, identidad de los productos gastronómicos y las tradiciones que surgen alrededor de ellos.

\section{Consentimiento informado}

Se elaboró un instrumento carta de autorización para que el participante de la entrevista exprese voluntariamente la participación en la investigación bajo su responsabilidad.

\section{Formato de la UNESCO}

También es importante mencionar que la UNESCO tiene el formato único para la elaboración de inventario de los patrimonios culturales tanto material como inmaterial, el cual se utilizará para ubicar los datos de aquellos productos gastronómicos emanados de la investigación que se encuentran en vía de desaparecer.

\section{Entrevista estructurada a Cocineros Empíricos, Amas de Casa y Campesinos}

La presente encuesta tiene como objetivo identificar cuáles son los principales platos típicos ancestrales del Núcleo Provincial Metropolitano de Santander. Esta información será exclusivamente de uso académico y se tratará de manera confidencial.

\section{Relacionado con La persona}

Nombre de la Persona Entrevistada:

Estado civil:

Hijos

Procedencia:

Profesión u oficio:

Lugar de la encuesta:

Hora:

Fecha:

\section{Nombre del plato}

Relacionado con el saber

1. ¿Cómo inicio su interés por la cocina?

2. ¿Con que frecuencia cocina usted?

3. ¿Quiénes han influenciado en sus habilidades para cocinar?

4. ¿Cree usted que ha ido cambiando la forma de preparar este (o estos) plato (s)?

5. ¿Cómo aprendió la receta? (de forma oral, escrita, visualizando)

6. ¿Quién ha mostrado interés en aprender su receta? Y ¿por qué?

\section{Relacionado con el plato}

7. ¿Qué utensilios utiliza para preparar este plato o producto?

8. ¿Qué combustible utiliza?

9. ¿Cuáles son los pasos (Pre alistamiento) para preparar su(s) plato (s)?

10. ¿Cuéntenos cómo prepara Usted este plato o producto, ingredientes, secretos, tiempo de preparación?

11. ¿Los productos que utiliza actualmente son los mismos que tiene la receta tradicional?, ¿Utiliza los mismos ingredientes?

\section{Relacionado con Tradición e Identidad}

12. ¿Cree usted que el plato o producto se consume actualmente o no se consume y ¿por qué?

13. ¿Cree que la tradición de elaborar estos platos está desapareciendo? Sí__ No__por qué?

14. ¿Le gustaría que las formas de preparación de este plato y/o producto se resguardaran en un documento para que permaneciera como identidad cultural de nuestra provincia? 


\section{Descripción del Instrumento}

El primer bloque de preguntas, del número 1 al 6 , está relacionado con el saber culinario de las personas. Allí se busca consultar, cómo se originó el interés por cocinar, cuál fue ese primer encuentro con la transformación de los alimentos y cómo aprendieron a cocinar. Otro aspecto significativo de este bloque de preguntas era averiguar si la receta aprendida se había transformado a través de los años, si la forma de la preparación de los alimentos era la misma o si ha cambiado con el paso de los años, y así, de este modo establecer la evolución de los platos investigados. Además, se buscaba indagar si sus familiares estaban interesados en aprender a preparar las recetas tradicionales.

En segundo lugar, las preguntas que van de la 7 a la 11 se enfocaron en los utensilios y equipos utilizados en la preparación de los platos; si se siguen usando los tradicionales y prácticas autóctonas desde el inicio, o si a medida que se van modernizando los cocineros han ido modificando sus utensilios. Otro factor primordial en la elaboración de la comida es el tipo de combustible utilizado; allí se explora si han cambiado la leña o el carbón, por combustibles más modernos. Lo mismo se pretende con los ingredientes; si han notado que estos se han transformado o si consideran que se han mantenido las mismas características organolépticas.

El último bloque de preguntas se buscaba establecer: por qué estos platos típicos no se preparan con la frecuencia con que se acostumbraba, con qué periodicidad se preparan hoy, por qué las personas han dejado de preguntarlos y de consumirlos, si las personas que poseen los saberes culinarios están enseñando este arte a las generaciones más recientes, si cada vez los productos se consiguen menos porque ya no se encuentra la materia prima; si el paso del tiempo, la tecnología y combustibles modernos han afectado la permanencia del plato entre los comensales. Por último, saber las causas por las cuales las nuevas generaciones no conocen estos alimentos.

\section{RESULTADOS}

A continuación, se describen los resultados del trabajo de investigación en el cual se tienen en cuenta los objetivos, los supuestos, la metodología y el marco teórico de esta investigación.

\section{Objetivo Específico 1}

Analizar las experiencias de recuperación del patrimonio cultural gastronómico de los países identificados por la UNESCO.

Se encontró que, en Francia, Italia, España, México y Perú, países referentes en el mundo para este tema, su principal fortaleza es la participación y colaboración entre todos los actores interesados en la salvaguarda de su patrimonio material e inmaterial. Para este caso, aquellos que tienen que ver con la cocina tradicional y autóctona; por esta razón, la UNESCO ha dado el aval para respaldar sus tradiciones y cultura gastronómica. Entre tanto, en Colombia existe la ley 1185 de 2008 donde se dictan normas sobre patrimonio cultural, fomentos y estímulos a la cultura.

España ratifico la convención para la salvaguardia del PCI, 2006 y dese entonces se ha llevado a cabo un trabajo muy activo con el resultado de 11 manifestaciones inscritas en la lista representativa del PCI y tres proyectos inscritos en el registro de buenas prácticas de salvaguarda del PCI de la Humanidad, convirtiendo de esta manera en el cuarto país con más elementos reconocidos. (Instituto del Patrimonio y Cultura de España, 2007)

La cocina italiana tiene su origen en la antigua roma, y su base principal es el aceite de oliva, que se da de forma excelente en la mayoría de sus regiones. Y con ellos la pasta que se conoce desde hace más de 3000 años, el arroz o risotto, el pan y el condimento de sus comidas. Y al igual que Francia, tiene unos vinos de primer orden y famosos en el mundo como el chianti, 
barolo y todos los de la comarca de la Toscana. Italia además tiene una gran industria de quesos, tiene más de 500 variedades de origen vacuno, ovina, caprina y de búfala. Tan reconocidos que son consumidos en todo el planeta. Son elaborados con las más altas técnicas de la industria de los lácteos y sus derivados; los más conocidos y referentes de la bota itálica son: mozzarella, parmesano, gorgonzola, provolone, ricota, feta. Que le han dado un gran renombre a Italia en el mundo de la Gastronomía (Martínez, 1992).

La gastronomía de Francia es considerada como Patrimonio Inmaterial de la Humanidad, además porque es la base de la cocina Occidental. Francia fue el primer país que se preocupó por desarrollar técnicas culinarias, por recopilar las recetas y la forma de hacerlas, por escoger alimentos de muy buena calidad para ofrecer al comensal un producto excelente en todos los aspectos, por la armonización de los manjares con los vinos o maridaje; así, el vino forma una parte muy importante de Francia ya que es uno de sus íconos y uno de los más valorados en el ámbito mundial. Y lo más importante, la relación y la armonía entre los seres humanos y la naturaleza. La sociedad francesa práctica el arte del buen comer y del buen beber. Se preocupan por conocer la tradición culinaria y preservar la memoria de esta; se preocupan por una práctica viva de los ritos gastronómicos y los transmiten, oralmente $\mathrm{o}$ por escrito, a las siguientes generaciones. Las autoridades francesas y entidades no gubernamentales se han preocupado por salvaguardar su gastronomía, fortaleciéndola y fomentando trabajos de investigación (UNESCO, 2009).

A los pueblos de Latinoamérica los llamaban cultura del maiz, ya que su alimentación se basaba en esta planta. La mayoría de los alimentos de la gastronomía prehispánica mexicana son a base de maíz, su variedad es tal que se conocen más de 500 productos derivados, los cuales se enriquecieron notablemente con la fusión que se hizo con los alimentos que trajeron los españoles al Nuevo Mundo. El aporte de España en ganado vacuno, ovino, y caprino hizo que evolucionara notablemente la cocina mexicana, colocándola a la vanguardia de las cocinas de mayor difusión y popularidad en el mundo (Fernández, 1985).

La cocina peruana es ahora una de las más conocidas del mundo. Esta diversificación se dio gracias la inmigración culturas como la española y en el siglo XIX con la de culturas como: africana, francesa, chino-cantonesa, japonesa e italiana. Todo esto mezclado con la herencia de los incas, conformó una fusión sin igual dando origen a la cocina moderna del Perú y a su constante evolución. Se debe destacar que la gran variedad de la gastronomía peruana se sustenta en tres fuentes: la geografía del Perú, la mezcla de razas y de culturas y la adaptación de culturas milenarias a la cocina moderna (Cahua, 2011).

También se debe señalar que el Proyecto Multinacional "Salvaguardia del Patrimonio Cultural Inmaterial de las Comunidades aymara de Bolivia, Chile y Perú", coordinado por CRESPIAL, recibió el reconocimiento dentro del registro de Buenas Prácticas del Patrimonio Inmaterial de la Humanidad de UNESCO, en febrero del año 2009. Este reconocimiento se otorga a las iniciativas que visibilizan los principios y objetivos de la Convención de UNESCO para la Salvaguardia del Patrimonio Inmaterial aprobada el año 2003.

\section{Objetivo Específico 2}

Identificar los platos típicos y/o productos gastronómicos característicos del Núcleo provincial Metropolitano que están en riesgo de desaparecer.

Los comentarios de los encuestados están basados en la entrevista estructurada aplicada.

En la tabla 1 se muestra la caracterización de la población entrevistada Amas de Casa, Hogares Campesinos, y Cocineros Empíricos sobre los platos y productos en riesgo de desaparecer. 
Tabla 1. Caracterización de la población: platos en riesgo de desaparecer.

\begin{tabular}{|c|c|c|c|c|c|c|c|c|}
\hline \multicolumn{2}{|c|}{ NOMBRE } & \multirow{2}{*}{$\begin{array}{c}\text { EDAD } \\
74\end{array}$} & \multirow{2}{*}{$\begin{array}{c}\text { LUGAR DE } \\
\text { NACIMIENTO }\end{array}$} & \multirow{2}{*}{$\begin{array}{c}\text { HIJOS } \\
\text { SI }\end{array}$} & \multirow{2}{*}{$\begin{array}{c}\text { AÑOS DE } \\
\text { RESIDENCIA } \\
\text { AMB } \\
55\end{array}$} & \multirow{2}{*}{$\begin{array}{c}\text { NIVEL } \\
\text { EDUCATIVO } \\
\text { 30. Primaria }\end{array}$} & \multirow{2}{*}{$\begin{array}{l}\text { OCUPACIÓN } \\
\text { Ama de casa }\end{array}$} & \multirow{2}{*}{$\begin{array}{c}\text { PLATOS } \\
\text { Arepas de } \\
\text { mazorca } \\
\end{array}$} \\
\hline 1 & A1 & & & & & & & \\
\hline 2 & $A 2$ & 62 & San Andrés (S.S.) & $\mathrm{SI}$ & 49 & $1^{0}$. Bachiller & Ama de Casa & Caspiroleta \\
\hline 3 & A3 & 61 & San Andrés (S.S.) & SI & 42 & Bachiller & Ama de Casa & $\begin{array}{c}\text { Sopa de } \\
\text { Chorotas } \\
\text { Sopa de } \\
\text { ruyas }\end{array}$ \\
\hline 4 & A4 & 57 & Girón & $\mathrm{SI}$ & 30 & $5^{0}$. Primaria & Ama de Casa & Turrón \\
\hline 5 & Ca1 & 66 & San Andrés (S.S.) & SI & 47 & $2^{0}$. primaria & Campesino & $\begin{array}{c}\text { Alfandoque } \\
\text { Rellenas de } \\
\text { Papa } \\
\text { Arepas } \\
\text { carisecas }\end{array}$ \\
\hline 6 & Ca2 & 67 & Málaga (S.S.) & SI & 53 & $5^{0}$. primaria & Campesino & $\begin{array}{c}\text { Cacao en } \\
\text { Bola }\end{array}$ \\
\hline 7 & Ca3 & 68 & Floridablanca & SI & 40 & $5^{0}$. Primaria & Campesino & $\begin{array}{c}\text { Ayacos de } \\
\text { Mazorca }\end{array}$ \\
\hline 8 & Co1 & 60 & Suratá (S.S.) & SI & 45 & $5^{0}$. Primaria & Cocinera & $\begin{array}{c}\text { Chanfaina, } \\
\text { Pichón, } \\
\text { Sopa de } \\
\text { venas } \\
\end{array}$ \\
\hline 9 & Co2 & 52 & Bucaramanga & $\mathrm{SI}$ & 52 & Bachiller & Cocinero & $\begin{array}{c}\text { Pata de res } \\
\text { acompañada } \\
\text { de yuca }\end{array}$ \\
\hline 0 & Co3 & 68 & Barichara & SI & 62 & $5^{0}$ - Primaria & Cocinero & $\begin{array}{c}\text { Cazuela de } \\
\text { criadillas }\end{array}$ \\
\hline 1 & $\mathrm{Co} 4$ & 53 & Lebrija & $\mathrm{SI}$ & 38 & $4^{0}$. Primaria & Cocinera & Mazamorra \\
\hline
\end{tabular}

Fuente: Elaboración propia de los autores

\section{Nomenclatura}

A1: ama de casa No.1, A2: ama de casa No.2, A3: ama de casa No.3, A4: ama de casa No.4.

Ca1: hogar campesino No. 1, Ca2: hogar campesino No.2, CA3: hogar campesino No 3.

Co1: cocinero No.1, Co2: cocinero No.2, Co3: cocinero No. 3, Co4: cocinero No.4.

Tomado como base los criterios de inclusión de la población el número de entrevistados fueron
11, tenían entre 52 y 74 años de edad, dentro del criterio de ocupación habían: 4 amas de casa, 3 campesinos y 4 cocineros empíricos. Todos los entrevistados tenían hijos; la mayoría de ellos venían de diferentes municipios de Santander del Sur: San Andrés, Surata, Onzaga, Barichara, Málaga, pero hace más de 30 años viven en el núcleo provincial metropolitano. A4, CA3, Co2, $6 \mathrm{Co} 4$ nacieron y viven en el área metropolitana de Bucaramanga: Floridablanca, Girón, Lebrija y Bucaramanga. También se debe decir que su 
nivel educativo es básico porque la mayoría han cursado apenas la primaria. De los 11 participantes solo A3 Y Co2 terminaron la básica secundaria o el bachillerato.

La edad es un factor relevante en esta investigación, dado que las personas de más de 50 años son quienes conservan y conocen la información que se busca en este trabajo y de ellos se obtienen los testimonios de las costumbres culinarias y de las tradiciones agrícolas, ganaderas y alimentarias que hay detrás de los platos que se consumían en sus épocas. Otro elemento relevante que se encuentra en la caracterización: hay 4 amas de casa, 4 cocineros y 3 campesinos. De este grupo, 4 son mujeres y 7 son hombres, lo que indica que a pesar de que Santander es una región identificada como una sociedad machista, los hombres también se han dedicado al arte culinario, pese a que era una labor, en su mayoría, exclusiva de las mujeres.

\section{Categoría transmisión oral y conocimientos culinarios}

Dentro del nivel educativo de los entrevistados se encontró que 9 participantes han cursado la básica primaria y dos han terminado el bachillerato. Ellos explicaban que en su época la educación no era la prioridad; la mayor parte de su tiempo lo dedicaban a las labores del campo Tampoco había capacitación en preparaciones alimenticias, pues la cocina giraba alrededor de lo que los padres o familiares enseñaban oralmente o por hábitos, lo cual significa que su conocimiento culinario era empírico. Este punto aplica a la categoría Conocimientos culinarios y tradición oral.

También se encontró que todos los entrevistados tienen hijos, pero al peguntarles si trasmitían estos saberes a sus descendientes, manifestaron que ninguno de ellos se interesaba en aprender dichas recetas, porque en esta época las personas que quieren cocinar están interesadas en las comidas rápidas, la cocina gourmet, la gastronomía internacional y no las comidas típicas; y muchos otros se han dedicado a estudiar y aprender otros artes. A su vez, Co2 y Co3 dijeron que otras personas allegadas a ellos, sí se han interesado por aprender, y que por esta razón los tienen como empleados en sus restaurantes.

En la población entrevistada se encontró que los participantes vienen de otras regiones de Santander, como la Comunera, García Rovira y Guanentina; pero que hace más de 30 años se migraron al área Metropolitana de Bucaramanga. Con este resultado se ve que el Núcleo Provincial Metropolitano, área de estudio de esta investigación, no tiene una identidad propia en la gastronomía, sino que las costumbres y recetas culinarias son heredadas de los demás pueblos de la región.

\section{Categoría, platos, Conocimientos productivos y consumos del ciclo diarios}

Las preparaciones alimenticias dependían de las cosechas que se daban en las épocas del año, el maíz por ejemplo se recogía entre Julio y agosto, se elaboraban ayacos de mazorca, arepas de mazorca con queso, arepas de maíz zarazo (maíz fresco casi seco). La cosecha de papa se recogía entre abril y mayo, este producto siempre estuvo y ha estado en diferentes formas de preparación en los platos de los hogares santandereanos.

De otra parte, comentaba $\mathrm{Ca} 3$, que quienes se encargaban de la alimentación de los obreros que trabajaban en sus fincas en trapiches o cultivando, debían preparar una serie de comidas y servirlas, es decir: a las 4:30 a.m. Café con arepa, luego el desayuno 7:00 a.m.: caldo con papa y huevo, algunas veces sin huevo y sin papa, llamada changua o chingüa, acompañado de arepa o trama (pan, mantecadas), chocolate o café. A la media mañana 10:30 a.m. servían café o chocolate con pan. A las 12:30 a 1:00 el almuerzo, sopa de ruyas o mazamorra o sopa de chorotas; la bebida era guarapo o agua de panela; a las 3:00 p.m. hora del puntal se comía: yuca con carne y guarapo. A la hora de la comida entre 5:00p.m. y 
6:00 p.m. se servía: papa o yuca, carne o huevo, acompañado de guarapo o aguapanela y una última comida llamada jiagua a las 12 de la noche: arroz, papa o arepa o yuca y huevo, algunas veces carne.

Así, los entrevistados fueron relatando sus historias a cerca de los platos que cocinaban sus ancestros (abuelos, madres, tíos y conocidos). Todos estos saberes culinarios fueron transmitidos de forma oral y mediante la práctica en cada una de sus cocinas, pero ahora no se encuentran ni se consumen con frecuencia en la vida cotidiana. Como resultado se logró elaborar un listado de los siguientes productos gastronómicos que han dejado de prepararse.

\section{Objetivo Específico 3}

Estructurar los contenidos para el diseño de una guía cátedra del patrimonio cultural gastronómico para el programa profesional de Gastronomía y alta cocina de la Universidad Autónoma de Bucaramanga, UNAB.

Para diseñar una guía de la cátedra "Patrimonio Cultural Gastronómico" del programa Profesional de Gastronomía y Alta Cocina de la UNAB, primero se debe tener coherencia con los lineamientos del Proyecto Educativo Institucional - PEI. Por tal razón, es importante mencionar en este momento el Fundamento Antropológico uno de los enfoques que constituyen el soporte teórico del PEI, el cual se refiere a la

"Reflexión filosófica que responda a la pregunta "¿Qué es el hombre?" ha de partir no sólo de la experiencia de quien reflexiona, sino de las construcciones elaboradas por las diferentes ciencias que estudian fenómenos humanos (Biología, Sociología, Historia, Psicología, Lingüística, Economía, Antropología
Física y Antropología Cultural, entre otras..." (Universidad Autónoma Bucaramanga, 2012)

De allí se derivan tres características que distinguen a los seres humanos referidas al ámbito biológico, psicológico y social.

Teniendo en cuenta los parámetros establecidos se estructuró la guía basada en tres grandes temas:

- La Unesco y la preservación de la memoria humana: es vital apreciar el componente cultural y patrimonial que existe detrás de las prácticas culinarias y aportar a la salvaguarda de este patrimonio basados en las premisas de la UNESCO, es así que identificar las materias primas, equipos, utensilios y técnicas de elaboración, conservación y almacenamiento tradicionales. quedarán preservadas en la memoria de quienes

- Etnogastronomía : es importante tener en cuenta los antecedentes históricos de algunas alimentos y preparaciones autóctonas colombianas comenzado por Santander, influencias ancestrales: indígena, española y africana, influencias gastronómicas de la región santandereana, tradiciones gastronómicas de Santander, preparaciones gastronómicas de todas las provincias santandereanas equipos, utensilios autóctonos, técnicas de procesamiento, conservación y almacenamiento implementadas en las regiones colombianas., materias primas ingredientes nativos, denominación de origen, desarrollo de productos autóctonos

- Desarrollo de productos autóctonos: donde se dará preponderancia a la manipulación de alimentos, características organolépticas, relación medio ambiente - practicas culinarias, innovación en el desarrollo y difusión de productos autóctonos. artefactos y utensilios ancestrales y sus cambios a través de la historia, uso y manejo de combustibles en los productos típicos santandereanos. 


\section{DISCUSIÓN}

Existen iniciativas en Patrimonio Cultural Inmaterial - PCI que tienen carácter regional, pero a la vez son limitadas para dar una respuesta adecuada al Patrimonio Cultural Inmaterial. En Santander, se encuentra información dispersa sobre el tema. Por ejemplo, libros como el de la Cocinanza Comedida de Estrella de los Ríos (2002), donde se aborda el tema de la gastronomía Santandereana y el Gran Libro de la Cocina Colombiana, en el cual dedica un capítulo a esta región, pero han dejado de ser impresos o reeditados.

Al Núcleo Provincial Metropolitano de Santander, NDPMS, han llegado inmigrantes, tal como se evidenció en las entrevistas realizadas, en la cual la población provenía de las diferentes provincias santandereanas, pero que habitan hace ya varios años en los municipios que forman parte del NDPMS. Podría decirse que el área de estudio de esta investigación no tiene una identidad propia en la gastronomía, sino que a las costumbres y tradiciones son heredadas. Esta conclusión se da con base en la pregunta formulada en esta investigación: ¿Cuáles son los aspectos socioculturales que caracterizan al NDPMS?

También, se encontró que al relatar sus historias acerca de los platos y productos que cocinaban sus ancestros (abuelos, madres, tíos y conocidos) los participantes admiten que todos estos saberes fueron transmitidos de forma oral y practicando tanto técnicas como modos de preparación en cada una de sus cocinas. Comentaban que muchas recetas se quedaron en la memoria de quienes dieron origen a la comida santandereana pero que ahora no los encuentran ni los consumen con frecuencia en la vida cotidiana.

Los chefs conocen los 16 productos que tienden a desaparecer, pero no los preparan, por esto no los incluyen en los menús de los restaurantes típicos, estos solo se encuentran en algunos restaurantes de las plazas de mercado o los preparan en los hogares campesinos. Lo anterior se debe a que no hay reconocimiento de la tradición y cultura gastronómica según lo emitido en las entrevistas y a que las preparaciones son muy elaboradas y necesitan de tiempo y espacio para su elaboración

Es importante destacar que los estudiantes tienen interés por aprender las recetas. Por esto es trascendental construir una cátedra para el programa de Gastronomía de la UNAB, que incluya temas que resalten la importancia de la preservación del patrimonio gastronómico como son: su historia , características de cada plato, materia prima, formas de preparación, la cultura gastronómica, como también conocer las entidades que aportan a la preservación y a su vez desarrollar en clase los productos de la gastronomía típica de las provincias santandereanas, comenzando por la del Núcleo Provincial Metropolitano de Santander. Esto ayudará a reconocer, valorar y dignificar la identidad cultural de los santandereanos.

\section{REFERENCIAS BIBLIOGRÁFICAS}

Cahua, J. (2011). Nina Mikhuna. Fusión de siglos y culturas. Recuperado de http://ninamikhuna. tripod.com/historiadelacocinaperuana.html

Convenio Andrés Bello.(2006). 361 Experiencias de apropiación social del patrimonio cultural y natural. Somos Patrimonio, (5), 103:113.

Cuervo, L. (1999). El rompecabezas de la intervención económica territorial. Territorios, 2, 77-93.

De Los Ríos, E. (2002). La cocinanza comedida. Bucaramanga: Universidad Autónoma de Bucaramanga.

Fernández, A. (1985). Tradicional cocina Mexicana y sus mejores recetas: México: Panorama editorial

García, M. (2011). El patrimonio cultural. Conceptos básicos. Zaragoza: Prensas Universitarias de Zaragoza.

Instituto del Patrimonio y Cultura de España. (2007). Ministerio de Educación, Cultura y Deporte. Plan Nacional del Patrimonio Inmaterial. Recuperado de http://ipce.mcu.es/ conservacion/planesnacionales/inmaterial.html 
Kottak, C. P. (2006). Antropología cultural. Barcelona: MacGraw Hill.

Martínez, M. (1992). Cocina italiana. Madrid: Libsa Editorial S.A.

Mindiola, M. (2006). Las representaciones regionales en la configuración del estado Nación: El santandereano en los discursos de José María Samper y Luis López de Mesa. Reflexiones Políticas. 8 (16) 150-162.

Ministerio de cultura. (2012). Política para el conocimiento, la salvaguardia y el fomento de la alimentación y las cocinas tradicionales de Colombia. Políticas culturales. Recuperado de http://www.mincultura.gov.co/ministerio/politicasculturales/Pol\%C3\%ADtica\%20de\%20 las $\% 20$ cocinas $\% 20$ tradicionales $\% 20 \mathrm{de} \% 20$ Colombia/Paginas/default.aspx

Núñez, A. 2012. Antropología y patrimonio en el contexto multicultural. Jangwa Pana 11, (40 - 48).
Pedro, G. V. (1977). La Otra Raya del Tigre. Madrid: Alianza editorial.

Querol, M. (2010). Manual de gestión del patrimonio cultural. Madrid: Ediciones Akal S.A.

Sánchez, E., \& Sánchez, C. (2006). Paseo de olla. Recetas de las cocinas regionales de Colombia Biblioteca básica de cocinas tradicionales colombianas. Bogotá: Ministerio de Cultura.

Serrano, E. (2007). Donde no te conozcan. Bogotá: Planeta.

UNESCO. (2003). Convención para la Salvaguardia del patrimonio cultural inmaterial. Paris.

UNESCO. (2009). CULTURA. Organización de las Naciones Unidas para la Educación, la Ciencia y la Cultura. Recuperado de http:// www.unesco.org/new/es/culture/

Universidad Autónoma Bucaramanga. (2012). Proyecto educativo institucional - PEI. 2, 2021. Bucaramanga, Santander: UNAB. 